\title{
Los arrendadores de las alcabalas en la tierra de Cuenca (1464-1470) *
}

\author{
Alcabala sales tax farmers in the district of Cuenca (1464-1470)
}

\author{
JULIÁN SÁNCHEZ QUIÑONES **
}

\begin{abstract}
RESUMEN
El siguiente trabajo versa sobre los personajes e instituciones que arrendaban las alcabalas de los sexmos de Cuenca entre 1464 y 1470. En este

artículo lo que se pretende es dar a conocer a estos individuos, señalando su procedencia familiar, las rentas a las que

solían pujar y la importancia de cada grupo social.
\end{abstract}

\section{PALABRAS CLAVE}

Cuenca, alcabalas, arrendadores, sexmos, familias, concejos.

\section{ABSTRACT}

In this work, we study the tax-farmers and the institutions that leased the alcabala sales tax in the fiscal district of Cuenca between 1464 and 1470. This paper intends to create a social portrait of these men, focussing on their family origin, the rents for which they were to bid, and the importance each social group acquired in this field.

\section{KEY WORDS}

Cuenca, alcabala sales taxes, tax-farmers, fiscal district, families, councils.

\section{INTRODUCCIÓN}

El presente trabajo versa sobre los arrendadores de las alcabalas en la tierra de Cuenca. En el mismo lo que vamos a analizar es quienes eran los personajes que arrendaban dicho impuesto, tratando de ubicarlos en el organigrama social de la localidad e indicando las posibles conexiones existentes entre ellos. Nuestro trabajo pretende ser un punto de partida para futuras investigaciones en este ámbito, por lo que en próximos trabajos nos centraremos en otros cargos, también relacionados con la alcabala, como serían los fiadores o los fieles. Para lograr

* Fecha de recepción del artículo: 2012-5-10. Fecha de aceptación del artículo: 2012-6-18.

** CEPA CANILLEJAS. Doctor en Historia Medieval por la Universidad Autónoma de Madrid. C.e.: julianquiones@yahoo.es. 
nuestro propósito hemos recurrido a una fuente poco utilizada: los cuadernos de alcabalas de Cuenca, concretamente los correspondientes al Legajo 140, Expedientes del 1 al 7, que cronológicamente abarcan desde 1464 a 1470.

\section{LOS ARRENDADORES DE LAS ALCABALAS EN LA TIERRA DE CUENCA}

\subsection{Introducción}

En un artículo relativo a los arrendadores de las rentas urbanas de Cuenca, ya dedicamos un amplio espacio a analizar a los hombres que se ocupaban de esta función. Entonces, obtuvimos unas interesantes conclusiones que nos pueden servir, con algunas variaciones, como punto de partida para el estudio de los arrendadores de la tierra de Cuenca ${ }^{1}$. Hay que señalar que para los sexmos se observan algunos cambios con respecto al caso urbano. Así, nos encontramos con que las élites urbanas no eran las únicas interesadas en las alcabalas de la tierra, sino que sufrían la competencia, tanto de los concejos aldeanos, como de personajes, no pertenecientes a la élite, poco conocidos y que ostentaban profesiones de tipo liberal como una escribanía. A todos ellos se unían, además, los vecinos de estas poblaciones que se atrevían a entrar en dicha carrera. Resulta por ello que en el campo circundante a la ciudad se daba una competencia mucho mayor que en el casco urbano, formando los personajes interesados un conjunto más heterogéneo que en el caso urbano. En nuestro trabajo vamos a analizar los grupos existentes, los sexmos donde pujaron con mayor asiduidad y las relaciones existentes entre ellos.

\subsection{Las élites urbanas}

La mayoría de los postores pertenecían a la élite de poder de la población que se dividía en dos grupos: lo que Jara Fuente denominó élite regimental y por debajo suyo, la élite de participación. El primer grupo eran linajes, podían ser nobiliarios o no, que contaban con una presencia preeminente en las regidurías del concejo $^{2}$. La segunda categoría, con mucha mayor presencia en este campo, eran familias que no tenían acceso a las regidurías o que habían perdido las que te-

1 Dichas observaciones eran las siguientes: 1) La mayoría de ellos pertenecen a la élite urbana, ya sea la de origen regimental o de la de participación. 2) Bajo número de ponedores y jerarquización por el número de rentas pujadas. 3) Control de ciertas rentas por parte de algunos individuos. 4) Se dan asociaciones entre individuos de manera repetida.

2 JARA FUENTE, J. A., Concejo, poder y élites. La clase dominante en Cuenca en el siglo XV, Madrid, ed. CSIC, 2000, pp. 104-127. A su vez los diferencia entre los que sirven oficios forales, de los que no, pp. 201-208. Para las familias nobiliarias indica que su escasa presencia sería fruto de que no lo 
nían. Su riqueza provenía del ganado y del arrendamiento de las rentas municipales y reales ${ }^{3}$. Este último grupo fue ascendiendo socialmente por medio de servicios, bien a la élite regimental, lo que les vinculaba al poder urbano o gracias a una prolongada carrera en las misiones que les encomendaba la ciudad. El arrendamiento de las rentas fue un mecanismo muy utilizado, como medio de vida y como manera de labrarse una brillante hoja de servicios, por lo que este grupo tuvo en las posturas efectuadas a las alcabalas una importancia crucial.

\section{a) Los linajes regimentales}

Entre los linajes regimentales podemos constatar la presencia de algunos muy destacados, fruto posiblemente de sus intereses en la tierra, ligados a los bienes inmuebles o al ganado que se localizaban en el alfoz urbano ${ }^{4}$. Aún así, no existió un gran interés hacia las alcabalas de la tierra, ya que ninguna de estas familias pujó a más de dos rentas. Entre las más relevantes hallamos los casos de los Alcalá y los Sacedón. Los primeros estaban representados por Juan González de Alcalá que en 1467 pujó a las alcabalas de Reíllo y Villar del Saz de Arcas ${ }^{5}$. Respecto a Juan de Sacedón, regidor de la ciudad desde 1459, éste se interesó ese mismo año por las alcabalas de Albalat ${ }^{6}$. En ambos casos la escasez de datos concuerda con el poco interés de estas familias por las alcabalas. Ni los Alcalá, que no solían prodigarse en estas lides y en concreto este individuo que tan sólo aparece en las alcabalas urbanas como fiel o fiador de terceros, ni los Sacedón, representados aquí por el citado regidor, solían hacer acto de presencia de modo frecuente en la subasta de estas rentas. Tal es así que Juan de Sacedón en las alcabalas urbanas, no pujaba tan siquiera, sino que se limitaba a avalar a otras personas o a sus familiares cercanos?

No obstante, otras familias sí prestaron más atención a esta actividad. Ello se debía a su posición secundaria dentro de la élite regimental, lo que les forzaba a optar a oficios de menor relevancia y a utilizar las alcabalas o rentas locales como vía para sus aspiraciones ${ }^{8}$. Entre ellos destacan los Molina, un linaje bien

necesitaban, al ser linajes con grandes patrimonios y además no lo juzgaban conveniente por su propia conciencia de clase. Ver: pp. 301-305.

3 GUERRERO NAVARRETE, Y., SÁNCHEZ BENITO, J. M., Cuenca en la Baja Edad Media: un sistema de poder, Cuenca, ed. Diputación Provincial de Cuenca, 1994, p. 138. Jara Fuente, J. A., op. cit. p. 208.

${ }^{4}$ Un caso claro de linaje con intereses inmobiliarios son los Alcalá. Los Molina serían el ejemplo perfecto de familia de ganaderos. Idem, pp. 144 y 149.

5 Juan González de Alcalá puja las alcabalas de Reíllo y Villar del Saz de Arcas. Ver: Archivo Municipal de Cuenca (A.M.C.U.) A.M.C.U.-Legajo 140-Expediente 4 (Alcabalas de 1467), fols. 51r-51v. Pedro López de Molina puja el sexmo entero de Altarejos el mismo año. Ver: Idem, fols. 5v-6r.

6 Idem, fol. 35r.

7 De hecho en las rentas urbanas no pujó ni una sola vez, limitándose a actuar como fiador de Juan de Torralba en la renta del pan en 1467. Idem, fol. 31v.

8 En las rentas municipales se centran en las del sello, la correduría, las sisas de la carne y del vino, o las sisas para el pago de la guerra. JARA FUENTE, J. A., op. cit. p. 302. 
representado en estos negocios, ya fuera por medio de Pedro López de Molina o de su hermano Francisco, ya que ambos actuaban como postores o como fiadores de sus familiares o de terceras personas ${ }^{9}$. En los sexmos aparece tan sólo el primero pujando en 1467 por el sexmo de Altarejos ${ }^{10}$. Otro caso prototípico de arrendadores habituales, lo forma la familia Castillo ${ }^{11}$, uno de cuyos integrantes, Gonzalo García del Castillo, pujó a las alcabalas y tercias de Fuentes en $1467^{12}$.

Se menciona además a un tal Juan de Jarava, vecino de Castillejo, lugar del sexmo del Campo, que pujó en 1467, junto con un convecino suyo, a las alcabalas de dicha localidad ${ }^{13}$. ¿Estamos ante un miembro de la familia de los Jaraba? No lo podemos aseverar con exactitud. No sería descabellado, pero no da esa impresión, tanto por la cuantía ofrecida por dichas rentas, como por el hecho de que a diferencia de los otros linajes, los Jaraba no se proyectaban en las rentas urbanas ni en las de la tierra. A pesar de ello seguían siendo una familia influyente, como lo prueba el hecho de que en este período dos de sus miembros formasen parte del regimiento, pero como en el caso de los Castillo o de los Molina su posición era totalmente secundaria ${ }^{14}$.

\section{b) Los linajes de participación}

Por debajo de ellos se situarían los linajes de participación. Un breve vistazo a la Tabla 1 nos aproxima rápidamente a las personas pertenecientes a este grupo:

Tabla 1: Miembros de los linajes de participación que arrendaron alcabalas en la tierra de Cuenca (1464-1470)

\footnotetext{
9 En 1464 Pedro es fiador de su hermano en la alcabala del vino. AMCU-Legajo 140-Expediente 4 (Alcabalas de 1467), fols. 3v-4r. Dos años después Pedro ejerció este mismo papel en la puja que Fernán Jiménez de Écija hizo en las varas y ropavieja. A.M.C.U.-Legajo 140-Expediente 3 (Alcabalas de 1466), fol. 3v. En 1469 Pedro pujó la renta de la madera. A.M.C.U.-Legajo 140-Expediente 6 (Alcabalas de 1469), fol. 4 r.

10 AMCU-Legajo 140-Expediente 4 (Alcabalas de 1467), fols. 5v-6r.

11 Eran arrendadores habituales tanto de las alcabalas como de las rentas concejiles. Acerca de sus actividades económicas, ver: GUERRERO NAVARRETE, Y., SÁNCHEZ BENITO, J. M., op. cit. pp. 145146. Son una familia que pierde su cargo de regidor y se situaban a un nivel similar al de los Molina, con los que ocupaban una posición secundaria en el concejo conquense. Sobre la pérdida de su regimiento ver: Ibidem. p. 204.

12 A.M.C.U.-Legajo 140-Expediente 4 (Alcabalas de 1467), fol. 5v. Este linaje muestra una mayor actividad en las rentas urbanas donde Juan del Castillo pujó a varias de ellas, monopolizando casi totalmente la de los cueros y zapateros. Ver: A.M.C.U.-Legajo 140-Expediente 4 (Alcabalas de 1467), fols. 57v, 59r-59v. A.M.C.U.-Legajo 140-Expediente 5 (Alcabalas de 1468), fols. 6r, 16r-16v, 26v, 32v, 33r. A.M.C.U.-Legajo 140-Expediente 7 (Alcabalas de 1470), fols. 20r-20v.

13 A.M.C.U.-Legajo 140-Expediente 4 (Alcabalas de 1467), fol. 4r.

14 Son Fernando de Jaraba, regidor entre 1468-1470 y Gutierre de Jaraba entre 1468-1469. Estos los habían conseguido por cesión del rey, que se los arrebató a García Ferrández de Alcalá y Gonzalo Núñez de la Muela, por sublevarse contra él. Sin embargo con su reconciliación, les devolvió dichos puestos y los dos Jarabas se quedaron sin ellos. Ver: Ibidem, pp. 108 y 123-124.
} 


\begin{tabular}{|c|c|c|c|c|c|c|c|c|}
\hline 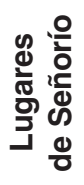 & 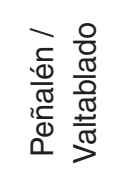 & & & 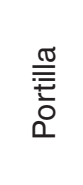 & & 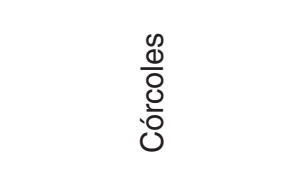 & & \\
\hline 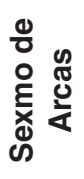 & 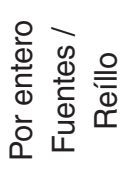 & & & $\begin{array}{l}\frac{1}{t} \\
\frac{0}{0} \\
\stackrel{0}{2}\end{array}$ & 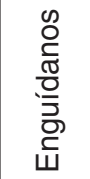 & 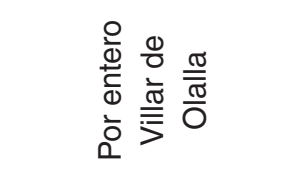 & 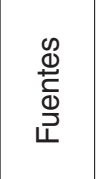 & $\frac{\mathscr{Q}}{\stackrel{\oplus}{\frac{1}{0}}}$ \\
\hline 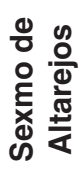 & $\begin{array}{l}\frac{0}{\Phi} \\
\stackrel{\frac{0}{c}}{0} \\
\frac{1}{0}\end{array}$ & & & 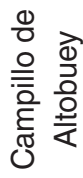 & & 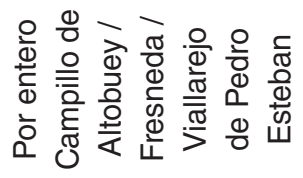 & 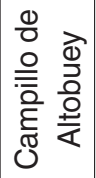 & \\
\hline 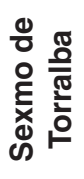 & 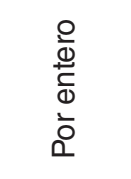 & & & & & 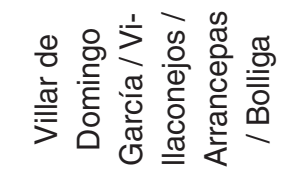 & & \\
\hline 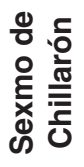 & 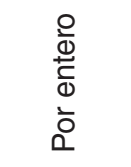 & & 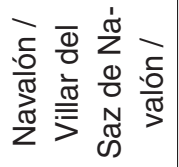 & & & $\begin{array}{l}\frac{0}{\frac{0}{d}} \\
\frac{\Phi}{0} \\
\frac{1}{0} \\
\square\end{array}$ & & \\
\hline 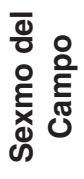 & 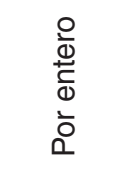 & & & & & 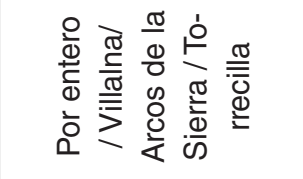 & & \\
\hline 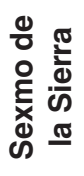 & 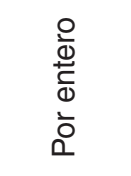 & 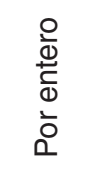 & & & & 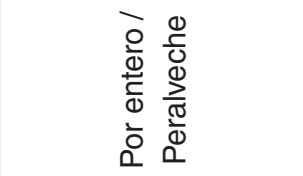 & & \\
\hline 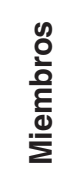 & 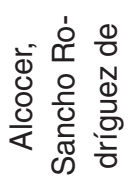 & 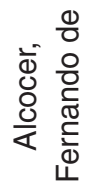 & 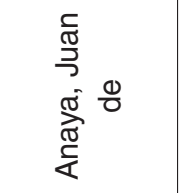 & 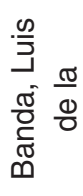 & 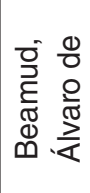 & 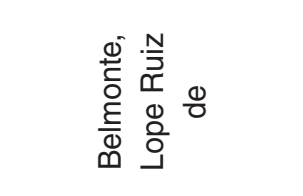 & 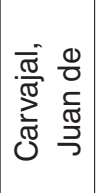 & 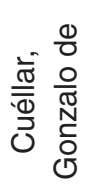 \\
\hline 芫 & $\begin{array}{l}\bar{む} \\
\text { ठ } \\
\frac{0}{\alpha}\end{array}$ & 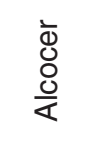 & $\begin{array}{l}\frac{\widetilde{d}}{\mathrm{~d}} \\
\frac{\mathrm{T}}{<}\end{array}$ & $\begin{array}{l}\frac{\pi}{0} \\
\frac{\mathbb{T}}{\infty} \\
\infty\end{array}$ & 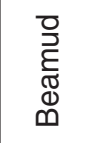 & 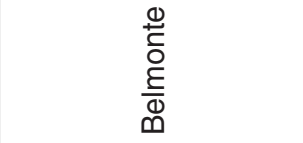 & $\frac{\sqrt[\widetilde{T}]{\frac{\mathbb{T}}{\mathbb{N}}}}{\stackrel{0}{J}}$ & $\frac{\frac{\bar{\sigma}}{\bar{d}}}{\frac{\bar{d}}{\bar{J}}}$ \\
\hline
\end{tabular}




\begin{tabular}{|c|c|c|c|c|c|c|c|}
\hline 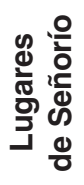 & & 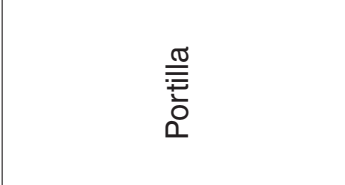 & & & & & \\
\hline 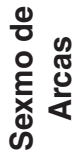 & & 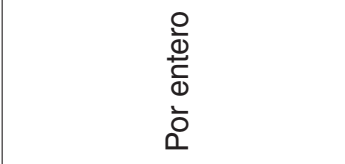 & 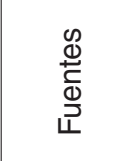 & & & 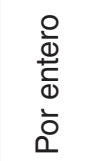 & \\
\hline 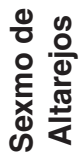 & & $\begin{array}{l}\frac{0}{\frac{0}{d}} \\
\frac{ \pm}{0} \\
\frac{1}{0} \\
\square\end{array}$ & & & & 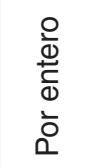 & 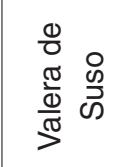 \\
\hline 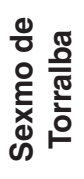 & & $\begin{array}{l}\frac{0}{\frac{D}{d}} \\
\frac{ \pm}{0} \\
\frac{1}{0} \\
\square\end{array}$ & & & 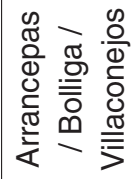 & & \\
\hline 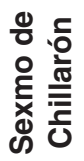 & & 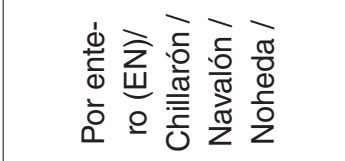 & & & & & \\
\hline 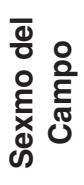 & & 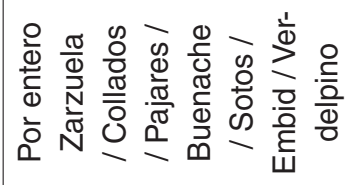 & & & & & \\
\hline 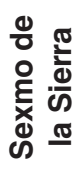 & 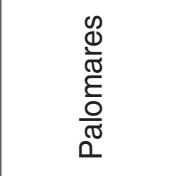 & & $\begin{array}{l}\frac{0}{0} \\
\stackrel{N}{N} \\
0 \\
0\end{array}$ & 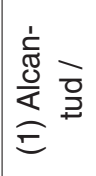 & 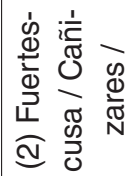 & & \\
\hline 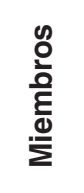 & 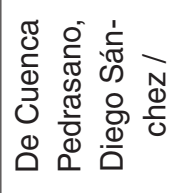 & 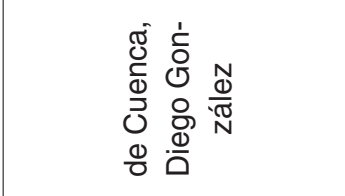 & 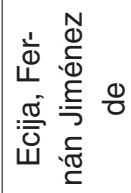 & $\begin{array}{ll} & \overline{0} \\
\frac{\pi}{0} & \frac{0}{0} \\
\frac{0}{0} & \frac{0}{4} \\
\text { E } & \frac{\overline{0}}{\square}\end{array}$ & 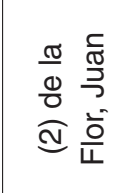 & 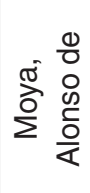 & 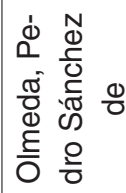 \\
\hline 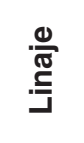 & 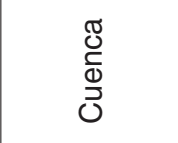 & 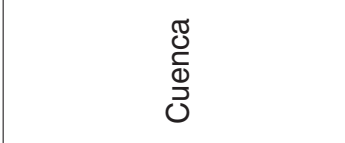 & : & $\begin{array}{l}\frac{\overline{0}}{\square} \\
\frac{\sigma}{0} \\
\frac{0}{0}\end{array}$ & $\begin{array}{l}\frac{1}{11} \\
\frac{\pi}{0} \\
\frac{0}{0}\end{array}$ & $\overbrace{\Sigma}^{\widetilde{\sigma}}$ & $\begin{array}{l}\frac{\pi}{0} \\
\stackrel{d}{E} \\
\stackrel{E}{0}\end{array}$ \\
\hline
\end{tabular}




\begin{tabular}{|c|c|c|c|c|c|c|c|}
\hline 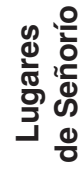 & & 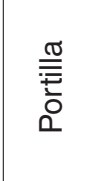 & & & & & \\
\hline 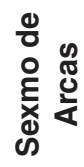 & $\begin{array}{l}\frac{O}{\Phi} \\
\frac{\Phi}{\frac{1}{0}} \\
\frac{1}{0} \\
\square\end{array}$ & & & & & & 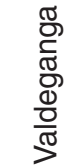 \\
\hline 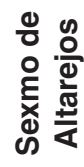 & 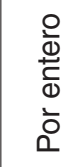 & & & & & & 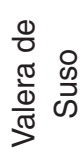 \\
\hline 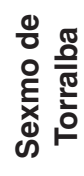 & & & & 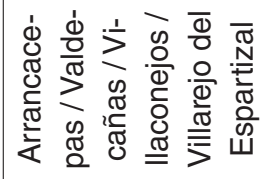 & 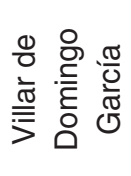 & 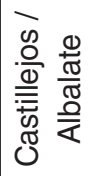 & \\
\hline 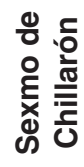 & & & & & & & \\
\hline 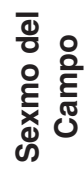 & & & 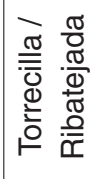 & 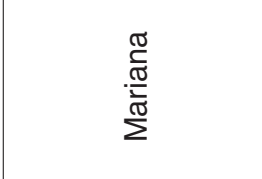 & & $\begin{array}{l}\frac{\pi}{0} \\
\frac{\pi}{\mathbb{d}} \\
\frac{\pi}{\pi} \\
\frac{0}{\pi}\end{array}$ & \\
\hline 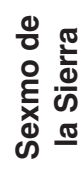 & & & & 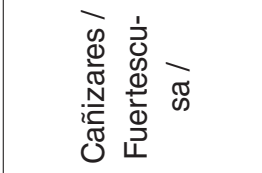 & & & \\
\hline 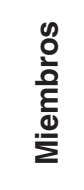 & 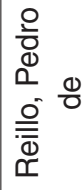 & 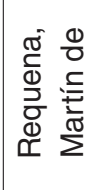 & 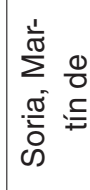 & 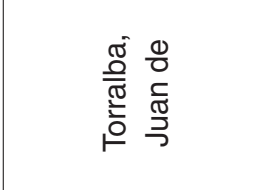 & 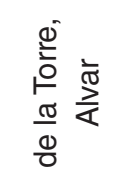 & 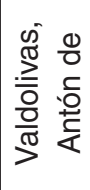 & 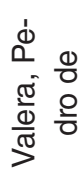 \\
\hline 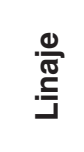 & $\begin{array}{l}\text { 음 } \\
\stackrel{\bar{\Phi}}{\simeq}\end{array}$ & 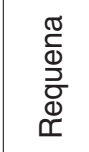 & $\begin{array}{l}\frac{\pi}{0} \\
\text { ஸ) }\end{array}$ & 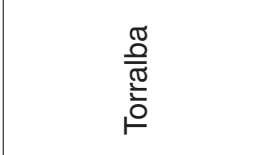 & $\stackrel{0}{\vdots}$ & 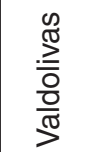 & $\frac{\frac{\pi}{0}}{\frac{\pi}{\pi}}$ \\
\hline
\end{tabular}


Hay 18 familias, lo que contrasta con el escaso número de linajes regimentales documentados. Los nombres aparecidos responden a los rasgos más típicos de estos grupos. En la mayoría de ellos un solo hombre solía concentrar tanto el poder político de la estirpe, como los intereses económicos que aquí se traducirían en las pujas realizadas a las alcabalas ${ }^{15}$. Es decir, existía una cabeza del linaje bien clara que se distinguía por su profusa actividad política, como regidor o con otro cargo, y rentística, ejerciendo como arrendador, por ejemplo, de la sisa del vino. Esto significaba que eran personas bien formadas para desempeñar el puesto al que se presentaban candidatos, ya que tenían experiencia previa en el cargo y por tanto eran idóneos para dicha misión. A ello ayudaba su constante presencia en las comisiones municipales relacionadas con estos temas, ya fuera por la entrada de intrusos en los términos concejiles o la resolución de problemas relacionados con el abastecimiento urbano ${ }^{16}$. Todo ello tenía su reflejo en la cantidad de ocasiones en las que aparecen como postores o arrendatarios en las alcabalas urbanas. Esto se puede apreciar en algunos casos concretos como Lope Ruiz de Belmonte, Sancho Rodríguez de Alcocer ${ }^{17}$, Juan de Torralba, Luis de la Banda, Alonso de Moya, Fernán Jiménez de Écija o Alonso de la Flor, que en este mismo período optaron en diversas ocasiones a estas rentas. Quizás Lope Ruiz de Belmonte sería el máximo exponente de esta actividad $^{18}$, pero sus compañeros también se hicieron notar en este cometido. Juan de Torralba, por ejemplo, controlaba la renta de la pelletería ${ }^{19}$. Asimismo, podemos mencionar a Alonso de la Flor, muy importante si se habla de la çerundaja ${ }^{20}$, o Fernán Jiménez de Écija, indispensable para varias de dichas alcabalas ${ }^{21}$. En el ámbito de la tierra, sin embargo, estos hombres jugaron un papel

15 JARA FUENTE, J. A., op. cit., p. 217.

${ }^{16}$ Algunos de ellos como Luis de la Banda solían ser miembros habituales de las mismas. Para una mejor comprensión de su composición ver: Jara Fuente, J. A., op. cit. pp. 241-248. Acerca de las rentas municipales y sus arrendadores ver la misma obra: pp. 305-320.

17 Puja la çerundaja, las bestias y heredades o los paños. A.M.C.U.-Legajo 140-Expediente 3 (Alcabalas de 1466), fols. 7r-7v. A.M.C.U.-Legajo 140-Expediente 4 (Alcabalas de 1467), fol. 12r. A.M.C.U.Legajo 140-Expediente 5 (Alcabalas de 1468), fol. 27v.

${ }_{18}$ En algunas de ellas, como la carne, fue el que más posturas presentó. Sobre sus posturas a la carne ver: A.M.C.U.-Legajo 140-Expediente 4 (Alcabalas de 1467), fols. 13r, 20v-21r, 22v. A.M.C.U.Legajo 140-Expediente 5 (Alcabalas de 1468), fols. 40r, 42r-42v. A.M.C.U.-Legajo 140-Expediente 6 (Alcabalas de 1469), fol. 2v. A.M.C.U.-Legajo 140-Expediente 7 (Alcabalas de 1470), fol. 5r.

19 A.M.C.U.-Legajo 140-Expediente 4 (Alcabalas de 1467), fols. 40v-41r, 64r; A.M.C.U.-Legajo 140-Expediente 5 (Alcabalas de 1468), fols. 40v-41r. A.M.C.U.-Legajo 140-Expediente 6 (Alcabalas de 1469), fols. 4r, 19r. A.M.C.U.-Legajo 140-Expediente 7 (Alcabalas de 1470), fol. 11r.

${ }_{20}$ A.M.C.U.-Legajo 140-Expediente 3 (Alcabalas de 1466), fols. 7r-7v. A.M.C.U.-Legajo 140-Expediente 4 (Alcabalas de 1467), fols. 5r, 30r, 52r, 55v-56r. A.M.C.U.-Legajo 140-Expediente 6 (Alcabalas de 1469), fols. $17 \mathrm{v}$ y $21 \mathrm{r}$.

${ }^{21}$ Como las varas y ropavieja, bestias y heredades y el pan. Para las varas y ropavieja ver: A.M.C.U.Legajo 140-Expediente 2 (Alcabalas de 1465), fols. 7r-7v. A.M.C.U.-Legajo 140-Expediente 3 (Alcabalas de 1466), fol. 3v. A.M.C.U.-Legajo 140-Expediente 4 (Alcabalas de 1467), fol. 16v. A.M.C.U.-Legajo 140-Expediente 6 (Alcabalas de 1469), fols. 11v-12r, 20r-20v. A.M.C.U.-Legajo 140-Expediente 7 (Alcabalas de 1470), fol. 4r. Para las bestias y heredades: A.M.C.U.-Legajo140-Expediente 4 (Alcabalas de 1467), fol. 4r. A.M.C.U.-Legajo 140-Expediente 6 (Alcabalas de 1469), fols. 11v-12r y 20r-20v. A.M.C.U.Legajo 140-Expediente 7 (Alcabalas de 1470), fols. 2v y 9r. Y para el pan: A.M.C.U.-Legajo 140-Expediente 5 (Alcabalas de 1468), fols. 8v-9r. A.M.C.U.-Legajo 140-Expediente 6 (Alcabalas de 1469), fols. 
secundario, probablemente porque las pujas estaban mucho más distribuidas. Efectivamente, los datos reflejados en la Tabla 1, nos muestran una gran dispersión geográfica en las posturas realizadas a los sexmos, pero hay que recordar que dentro de la misma, no están recogidas ni las efectuadas por la élite regimental, ni las de los concejos o particulares. Esto provocaba que el dominio sobre las alcabalas de la tierra no fuese tan aplastante como en el ámbito urbano, donde la competencia era menor.

Junto a las familias señaladas aparecen otras que tenían una menor presencia. Los Soria, Carvajal, Reillo, Anaya, Olmeda o Cuéllar, igualmente pertenecían a la élite de participación y por tanto tenían sus mismas características, estando vinculados a algunos de los linajes más importantes y desempeñando oficios ligados al regimiento ${ }^{22}$. Por tanto existen pocas dudas sobre los integrantes de estos linajes, salvo algún caso en concreto ${ }^{23}$.

El siguiente punto sería conocer el verdadero peso de la élite de participación en las pujas efectuadas durante este período. Para ello es necesario conocer como se realizaban las posturas a los sexmos. Estas podían podían hacerse por entero, esto es a la totalidad del sexmo, o por partes, es decir tan sólo a una o varias de las aldeas de la tierra. Ambas formas eran válidas y los postores emplearon las dos indistintamente ${ }^{24}$. En este sentido no hay que dejarse engañar por las apariencias. Algunos linajes aparecen como pujadores en las alcabalas de todos los sexmos, pero, a pesar de ello, el número total de sus posturas era bajo. El caso más evidente podría ser el de Sancho Rodríguez de Alcocer que en 1467 presentó ofertas a los seis sexmos por entero, más los lugares de Peñalén y Valtablado ${ }^{25}$. Sin embargo, después de dicha puja apenas vuelve a aparecer. Y el resto de los linajes, salvo algunos casos concretos como Diego González de Cuenca ${ }^{26}$, Lope Ruiz de Belmonte ${ }^{27}$, Juan de

2r, 11v-12r. AMCU-Legajo 140-Expediente 7 (Alcabalas de 1470), fol. 2v. En 1470 pujó a las tres rentas: A.M.C.U.-Legajo 140-Expediente 7 (Alcabalas de 1470), fols. 15r, 18v, 19r y 21r-21v.

22 Es el caso de los Olmeda ligados bien a los Álvarez de Toledo o los Guadalajara. Jara Fuente, J. A., op. cit. p. 211, nota 261. Los Reíllo por su parte se vinculaban a los Guadalajara y los Molina, p. 216 nota 263.

23 Juan de la Flor, no tenemos muy clara su pertenencia al linaje. Consta como vecino de Priego. Ver: A.M.C.U.-Legajo 140-Expediente 4 (Alcabalas de 1467), fol. 69v. Lo mismo cabe decir de Juan Redondo, de profesión cardador. Podría pertenecer al linaje de los Redondo. A.M.C.U.-Legajo 140-Expediente 5 (Alcabalas de 1468), fol. 24r.

${ }^{24}$ Idem, fols. 3v, 38v-39r, 45v-47r. Idem, fol. 1v. A.M.C.U.-Legajo 140-Expediente 6 (Alcabalas de 1469), fols. $5 v-6 r$.

${ }_{25}$ Idem, fols. 6r-7r.

26 Diego González de Cuenca presentó posturas en 1467 a las alcabalas de Zarzuela, Palomera, Portilla, Chillarón, Sotos y Buenache. Idem, fols. 7r, 13v, 14v-15r, 20r-20v, 27v, 49v, 58v, 62r-62v, 68v. En 1468 hizo lo propio con las rentas de Embid, Verdelpino, Zarzuela y Collados lugares del sexmo del Campo y de Pajares, Chillarón y Nohales, lugares del sexmo de Chillarón. Ver: Ibidem, fols. 6r-6v, 22r. Asimismo en 1468 presentó pujas por entero a todos los sexmos salvo el de la Sierra, ver: Idem, fols. 12v-13r.

27 En 1467 pujó a las alcabalas de Peralveche, Arrancacepas, Bolliga, Villar de Domingo García, Villaconejos, Villalna y Arcos de la Sierra. Idem, fols. 17r, 23r, 25r, 52v, 59r y 64v. Al año siguiente presentó un "arrendamiento en masa" a todos los sexmos de la tierra, más el lugar de Córcoles. Ibidem, fols. 15r y 16r y además se le remataron las rentas de Torrecilla, Campillo de Altobuey, Villarejo de Pedro Esteban y Fresneda, fols. 26r y $29 r$. 
Torralba ${ }^{28}$ o Luis de la Banda ${ }^{29}$, optaron como mucho a las rentas de uno o dos sexmos, con un número bajo o muy bajo de ofertas.

Su concurso además lo solían hacer en solitario. Las posturas de dos o más personas eran muy raras. Una de las pocas documentadas fue la efectuada por el cuarteto compuesto por Pedro de Reillo, Juan de Arnedillo, Juan del Abad y Alonso de Moya que intentaron hacerse con las alcabalas de los sexmos de Altarejos y Arcas de 1466 y $1467^{30}$. De los cuatro, tan sólo dos pertenecían a la élite de poder, siendo Juan de Arnedillo y Juan del Abad unos vecinos de Reillo y Mohorte, respectivamente. Sin embargo, estas «asociaciones» fueron poco frecuentes y carecieron de continuidad en el tiempo, por lo que no podemos hablar de la constitución de compañías o siquiera de asociaciones arrendaticias de carácter tempo$\mathrm{ral}^{31}$. Esta ausencia podría explicarse, en cierto modo, por el bajo precio de las rentas de los sexmos, en especial si se arrendaban tan sólo algunas de sus aldeas. $Y$ es que las rentas aldeanas solían ser bastante baratas e incluso cuando se arrendaban «en masa», su precio era asequible ${ }^{32}$.

Para hacerse una idea de ello, podemos mencionar el «arrendamiento en masa» que efectuó Diego González de Cuenca en diversos lugares de los sexmos del Campo y de Chillarón. En 1468 pujó a las alcabalas de las aldeas de Zarzuela, Collados, Pajares, Chillarón, Sotos, Buenache, Noheda y Navalón, por un precio de tan sólo 9.420 maravedís ${ }^{33}$. Meses más tarde hizo una oferta similar cuya cuantía era casi ridícula: 7.883 maravedís. En esta ocasión conocemos lo que ofreció por cada uno de los sitios ofertados y lo cierto es que su valor era muy reducido: Embid: 80 maravedís; Verdelpino 50; Zarzuela 3.330; Pajares con Collados, 425; Noheda 228; Nohales y Chillarón $3.370^{34}$. Por supuesto, todo dependía

${ }^{28}$ Por su parte Juan de Torralba hizo posturas a las alcabalas de Arrancacepas, Cañizares, Fuertescusa, Villarejo del Espartizal, Villaconejos, Valdecañas y Mariana. Idem, fols. 32v, 34v, 35r, 59v-60r.

${ }^{29}$ Luis de la Banda hizo una postura a las rentas de Mohorte, Portilla en 1467. A.M.C.U.-Legajo 140-Expediente 4 (Alcabalas de 1467), fols. 16v, 20v, 53v. Al año siguiente volvió a repetir con Portilla y además ofertó las alcabalas de Ribatejada y Torrrecilla. A.M.C.U.-Legajo 140-Expediente 5 (Alcabalas de 1468), fols. 2r, 4v. En 1469 lo intentó con Campillo de Altobuey y Portilla. A.M.C.U.-Legajo 140-Expediente 6 (Alcabalas de 1469), fol. $6 \mathrm{v}$.

30 Idem, fol. $41 \mathrm{v}$.

31 Acerca de esta cuestión se puede consultar: *DIAGO HERNANDO, M., «Arrendadores arandinos al servicio de los Reyes Católicos» en Historia, Instituciones, Documentos (HID), 18 (1991), pp. 71-96, sobre todo, pp. 73-82, donde analiza las relaciones de Pedro de Santa Cruz o Francisco Berlanga con las compañías de los arrendadores castellanos o en las que ellos mismos intervenían. Ver también: ALONSO GARCÍA, D., «Poder financiero y arrendadores de rentas reales en Castilla a principios de la Edad Moderna» en Cuadernos de Historia Moderna, 31 (2006), pp. 117-138. Para la submeseta sur se deben consultar: *JARA FUENTE, J. A., «Elites y grupos financieros en las ciudades castellanas de la Baja Edad Media» en En la España Medieval (EEM), 27 (2004), pp. 105-130. GONZÁLEZ ARCE, J. D, La fiscalidad del señorío de Villena en la Baja Edad Media, Albacete, ed. Instituto de Estudios Albacetenses Don Juan Manuel, 2002, pp. 359-367.

32 Los «arrendamientos en masa» designan una operación, consistente en pujar por un conjunto de alcabalas, generalmente tres o más, para obtener un oligopolio sobre dicha renta. LADERO QUESADA, M. A., La Hacienda Real en Castilla (1369-1504), Madrid, ed. Real Academia de la Historia, 2009, p. 26.

33 Ibidem, fol. 6v.

34 Idem, fol. 22r. 
del valor de las alcabalas en cada lugar, pero el importe casi nunca superaba los 10.000 maravedís.

A pesar de ello había lugares que por sí solos suponían una cifra más que respetable. Son los casos de Fuentes, que llegó a pujarse por 8.000 maravedís o Campillo de Altobuey que llegaba hasta los $21.000^{35}$. Lo mismo cabe decir de otros sitios como Cañizares, Fuertescusa, Valera de Suso ${ }^{36}$, Chillarón o Sotos ${ }^{37}$. Sin embargo, si se comparan estas cifras para las documentadas en las alcabalas urbanas, el nivel al que podrían equipararse sería el de una renta media o baja, es decir por debajo de los 10.000 maravedís o incluso de los 5.000. Pero es que ni siquiera cuando las rentas se arrendaban o se pujaban por entero, podemos encontrar valores realmente elevados. El sexmo más valioso era el de la Sierra, que en 1467 valía 60.000 maravedís, junto con Peñalén y Valtablado. $\mathrm{Su}$ valor se fue incrementando en los meses siguientes hasta llegar a los 204.000 por las alcabalas de 1466 y 1467, es decir 102.000 maravedís por cada año, un incremento del 40 \%. En contraste, el precio de los sexmos del Campo, Torralba y Chillarón, ascendió en una primera postura a tan sólo 30.000 por los tres y los 40.000 de Arcas y Altarejos ${ }^{38}$. Estos dos últimos fueron los más valorados tras el sexmo de la Sierra, con una puja de 102.000 maravedís por los años $1466-1467^{39}$, es decir 51.000 por cada sexmo. Si comparamos estos precios con las alcabalas urbanas, las rentas del vino o de la çerundaja o la carne, podían llegar a estas cifras casi sin esfuerzo. Si desglosamos la primera oferta por los sexmos del Campo, Chillarón y Torralba, estos valían tan sólo 10.000 maravedís, es decir, más o menos el nivel de una renta media-baja urbana. No es de extrañar por tanto, que los arrendadores prefirieran pujar en solitario, por cuanto no necesitaban de apoyos para garantizar el éxito de su gestión. La «asociación» entre Pedro de Reillo, Juan de Arnedillo, Juan del Abad y Alonso de Moya, era sin duda necesaria, dado que se comprometieron a pagar los 102.000 maravedís indicados por los sexmos de Arcas y Altarejos. Pero en los demás casos, en los que los importes eran por norma general, muy inferiores, tal requisito no era indispensable.

Lo que sí se puede indicar, sin género de dudas, es la mayor querencia de estos personajes por las alcabalas de un sexmo u otro. Esto podría explicarse por la coincidencia de sus intereses rentísticos, patrimoniales y ganaderos en una

\footnotetext{
35 Idem, fols. 24 r y 29r. Posteriormente el valor de las rentas de Fuentes descendió a 7.000 maravedís, fols. 28r-28v. Sin embargo al principio del año, por las alcabalas de Campillo de Altobuey sólo se ofrecieron 2.500 maravedís. Ver: Idem, fol. 4v.

${ }^{36}$ Juan de Torralba pujó en 1467 las alcabalas de Cañizares por 3.000 maravedís y las de Fuertescusa por 5.000 maravedís. Meses después, el valor conjunto de las mismas, unido al de Bolliga ascendía a 10.060 maravedís. A.M.C.U.-Legajo 140-Expediente 4 (Alcabalas de 1467), fols. 34v-35r y 69v. Las de Valera de Suso lo fueron por Pedro de Valera por 4.282 maravedís. Ver: Idem, fols. 23r-23v.

37 Diego González de Cuenca hizo una postura por ellas que ascendía a 3.000 maravedís por Chillarón, 2.300 por Sotos y 1.120 por Buenache. Idem, fol. $68 \mathrm{v}$.

38 Dicho «arrendamiento en masa» fue efectuado por Sancho Rodríguez de Alcocer. Idem, fols. 6r-7r.

39 Idem, fol. $41 \mathrm{v}$.
} 
demarcación concreta de la tierra. En este sentido, cabe señalar que algunos de los linajes indicados disponían de importantes bienes pecuarios y relacionados con la industria textil ${ }^{40}$. La Tabla 2 ofrece una relación de los sexmos más pujados por cada una de estas familias.

Tabla 2: Linajes conquenses con los sexmos o lugares de señorío donde más pujaron a las alcabalas

\begin{tabular}{|l|l|}
\hline \multicolumn{1}{|c|}{ Linaje } & Sexmo / Lugar de señorío \\
\hline Alcocer & Arcas/Sierra \\
\hline Anaya & Chillarón \\
\hline Banda & Portilla \\
\hline Beamud & Arcas \\
\hline Belmonte & Altarejos/Campo/Torralba/ \\
\hline Carvajal & Altarejos/Arcas \\
\hline Cuellar & Altarejos/Arcas \\
\hline Cuenca & Campo/ Chillarón \\
\hline Ecija & Arcas/Sierra \\
\hline de la Flor & Sierra/ Torralba \\
\hline Moya & Altarejos/Arcas \\
\hline Olmeda & Altarejos \\
\hline Reillo & Altarejos \\
\hline Requena & Portilla \\
\hline Soria & Campo \\
\hline Torralba & Torralba \\
\hline Torre & Torralba \\
\hline Valdolivas & Torralba \\
\hline Valera & Altarejos/Arcas \\
\hline & \\
\hline
\end{tabular}

40 Guerrero Navarrete y Sánchez Benito señalan que todas estas familias tenían una orientación económica dedicada hacia las rentas, la ganadería y la industria textil. GUERRERO NAVARRETE, Y., SÁNCHEZ BENITO, J. M., op. cit., p. 167. 
En la tabla se incluyen sólo aquellos sexmos que gozaron de una atención preferencial por el linaje respectivo. En los casos en que se limitan a una sola puja en dos o más de estos lugares, los hemos incluido todos, por entender que no había una preferencia clara por uno de ellos. La excepción a esta regla son los linajes Cuenca y Belmonte, que prestaron atención a dos o más sexmos. Descartadas estas dos familias, las demás se centraron en ciertas alcabalas de Arcas y Altarejos. Aquí, los Cuéllar, Carvajal, Valera, Alcocer o Moya, dedicaron su atención a aldeas de probada solvencia y rentabilidad, como Campillo de Altobuey, Fuentes o Valera de Suso ${ }^{41}$. El resto de pujas fueron por entero o se hicieron en otras localidades como Mohorte y Valdeganga. Para los linajes que pujaron a un solo sexmo, también hubo coincidencia en sus pujas. En el sexmo de Torralba las poblaciones más solicitadas eran Arrancacepas, Bolliga, Villaconejos y Villar de Domingo García $^{42}$. En la Sierra, Cañizares y Fuertescusa ${ }^{43}$. Finalmente en del Campo, predominaron Ribatejada y Torrecilla ${ }^{44}$, mientras que en Chillarón, la dinámica era diferente, por cuanto los únicos que pujaron aquí con cierta frecuencia, y no siempre coincidían en las aldeas, fueron los Anaya y los Cuenca ${ }^{45}$. Entre los lugares de señorío predominó Portilla, puesta en precio por los Banda, Cuenca y Requena.

Finalmente en lo que concierne a los lazos de parentesco existentes y las profesiones que desempeñaban, hay que decir que no se indica ningún tipo de relación consanguínea entre los arrendadores. Sí podemos indicar algunos de los familiares cercanos, dado que se mencionan ocasionalmente, pero no parece que esto fuese un factor decisivo a la hora de intervenir como socio en el negocio. Así, de Fernando de Alcocer sabemos que era hijo de Sancho Rodríguez de Vétera ${ }^{46}$; Martín de Soria lo era de Gonzalo Fernández de Soria ${ }^{47}$ y Miguel de la Torre, de Alvar Sánchez de la Torre ${ }^{48}$. Fuera del vínculo paterno-filial lo más cercano que tenemos es a Juan de Anaya y Juan de Sacedón, que eran yerno y suegro respectivamente ${ }^{49}$. Mucho más relevantes fueron las profesiones que desempeñaron.

${ }^{41}$ Fuentes fue pujada por los linajes Alcocer, Carvajal, Cuéllar y Écija. Campillo de Altobuey por los Banda, Belmonte y Carvajal. Valera de Suso por los Olmeda y los Valera.

42 Pujadas por los Belmonte, los de la Flor, Torralba y de la Torre.

43 Presentaron ofertas los de la Flor y los Torralba.

44 Ofertadas por los Belmonte, Soria y Valdolivas.

45 La excepción fue Navalón.

46 Como Sancho Rodríguez de Alcocer pertenecen los tres al mismo linaje. Ahora bien, en este linaje había dos ramas, una más política, dirigida por Luis Ferrández de Alcocer y la económica, ligada al arrendamiento de rentas que dirigía el citado Sancho Rodríguez de Alcocer. Es factible que Fernando de Alcocer, tanto por el apellido paterno como por su dedicación a las rentas fuese miembro de esta segunda rama. JARA FUENTE, J. A., Concejo..., pp. 218-219. A.M.C.U.-Legajo 140-Expediente 4 (Alcabalas de 1467), fol. 58r.

47 A.M.C.U.-Legajo 140-Expediente 5 (Alcabalas de 1468), fol. 2r. Esta familia se hallaba bien relacionada con los demás linajes: Molina, Cañizares, Deza o Cuenca. Como los Alcocer se dividían en dos ramas, encabezadas por los hermanos Alvar y Diego Gil de Soria y con gran experiencia en los arrendamientos de rentas. El padre de Martín de Soria, Gonzalo, fue fiel de caballero de la sierra en 1430-1431 y el mismo Martín, caballero de la sierra. Idem, pp. 221-222, nota 264.

48 Ibidem, fol. 60v.

49 Ibidem, fol. 32r. 
Contamos con un predominio amplio de los escribanos, hay seis ${ }^{50}$, un portero mayor del rey ${ }^{51}$, un alcalde ordinario ${ }^{52}$ y un barbero ${ }^{53}$. La composición socioprofesional de estos individuos no era ni mucho menos casual, dado que ninguno de ellos pertenecía a los linajes regimentales y por ello no debían temer mancharse con unos oficios que, en algunos casos, rozaban lo insultante, como podía ser el de barbero. El predominio de las escribanías reflejaba perfectamente como habían ido apropiándose de ellas, en contraste con las familias más importantes de Cuenca que sólo las ocupaban de manera ocasional ${ }^{54}$. De igual modo el servicio al rey podía permitir la promoción de un linaje concreto, no sólo a este nivel, sino también en el caso de la alta nobleza patrimonial conquense ${ }^{55}$.

\subsection{Los concejos rurales y los vecinos de la tierra}

\section{a) Los concejos}

Las instituciones concejiles también pujaron a las alcabalas de la tierra. Su papel dentro de este juego era menor, documentándose tan sólo unas cuantas posturas, principalmente en el año 1467 y tan sólo en unos pocos casos se les remataron las rentas:

Tabla 3: Posturas de los concejos a las alcabalas de los sexmos de Cuenca (1464-1470)

\begin{tabular}{|c|c|c|c|}
\hline Año & Concejos & Renta & Cantidad \\
\hline 1467 & La Puerta & La Puerta & 4.080 \\
\hline 1467 & Cereceda & Cereceda & 1.020 \\
\hline 1467 & Mantiel & Mantiel & 2.040 \\
\hline 1467 & Zarzuela & Zarzuela & $\begin{array}{c}\text { Mayor precio que dieron } \\
\text { en 1464-1465 }\end{array}$ \\
\hline 1467 & Reíllo & Reíllo & 2.040 \\
\hline
\end{tabular}

50 Pedro de Valera, Diego Sánchez de Cuenca Pedrasano, Diego González de Cuenca, Luis de la Banda, Sancho Rodríguez de Alcocer y Álvaro de Beamud. Ibidem, fols. 8r, 12r, 13v, 16v, 50r. Ibidem, fol. 25 r.

51 Juan de Anaya. Ibidem, fol. 34r.

52 Juan de Carvajal. Ibidem, fol. 4v.

53 Antón de Valdolivas. Ibidem, fol. 53r.

54 Sobre esta cuestión: Ibidem, pp. 281-284.

55 A este respecto ver: *ORTEGA CERVIGÓN, J. I., «Prestigio político y oficios reales: la nobleza conquense bajomedieval en el entorno cortesano» en Anuario de Estudios Medievales (AEM), 37/2 (2007), pp. 563-595. 


\begin{tabular}{|c|c|c|c|}
\hline Año & Concejos & Renta & Cantidad \\
\hline 1467 & La Parra & La Parra & 1.886 \\
\hline 1467 & Campillo de Altobuey & Campillo de Altobuey & 21.076 \\
\hline 1467 & Valera de Suso & Valera de Suso & $4.287(\mathrm{R})$ \\
\hline 1467 & Arcos de la Cantera & Arcos de la Cantera & $1.300(\mathrm{R})$ \\
\hline 1467 & Tondos & Tondos & 500 \\
\hline 1467 & Córcoles y Valdeloso & Córcoles y Valdeloso & $4.000^{*}$ \\
\hline 1468 & Chillarón & Chillarón & $3.800(\mathrm{R})$ \\
\hline 1468 & Albalate & Albalate & $6.250(\mathrm{R})$ \\
\hline 1469 & Campillo de Altobuey & Campillo de Altobuey & $\begin{array}{c}30.300 \text { y diez pares } \\
\text { de gallinas }\end{array}$ \\
\hline $1469-1470$ & Huélamo & Huélamo & $18.000^{*}(\mathrm{R})$ \\
\hline
\end{tabular}

* Por cada año (R) Rematadas

Muy pocas alcabalas recayeron en manos de los regimientos rurales, posiblemente debido a que sus posibilidades económicas eran bastante limitadas. Los análisis sociológicos efectuados sobre los concejos de la zona, concretamente sobre la aldea de Fuentes, confirman esta impresión. La mayoría de sus vecinos carecían de tierras, muy pocos contaban con un número de cabezas de ganado reseñable y respecto a sus niveles de ingresos, hay que decir, que aunque había un número relativamente alto de posteros, la mayoría de la población tenía muy pocos recursos ${ }^{56}$. Tomando, por tanto, esta localidad como ejemplo de muestra, lo lógico sería plantear que el nivel adquisitivo de estos concejos no les permitía hacerse con las citadas rentas.

Sin embargo, se dieron casos en los que los municipios optaron a las alcabalas más caras de la tierra. Esto tendría su explicación en que al ser un impuesto que se cargaba sobre las compraventas, estas tendrían una mayor importancia en ciertos sitios, como Campillo de Altobuey, Albalate o Huélamo. Aún así, no supusieron una amenaza seria al poder de las grandes familias urbanas. Para estos linajes invertir 20.000 o 30.000 maravedís era algo relativamente habitual y si no insistieron en hacerse con estas rentas, fue porque sus intereses se hallaban en

\footnotetext{
${ }^{56}$ Los posteros en la tierra de Cuenca señalan el límite máximo de tributación fiscal. Equivalían a 8 centenas y cada postería a su vez a unos 20.000 maravedís, si bien estas cifras hay que tomarlas con extrema prudencia. SÁNCHEZ BENITO, J. M, «Estructura social de un pueblo de Castilla en época de Ios Reyes Católicos: Fuentes, aldea de Cuenca» en EEM, 31 (2008), pp. 97-122, sobre todo 100-109.
} 
otro sitio. Con todo, un análisis comparativo de las principales inversiones de dichos linajes, muestran algunas coincidencias llamativas con las ofertas presentadas por los concejos. En Campillo de Altobuey, por ejemplo, las autoridades municipales entraron en competencia directa contra Juan de Carvajal, Luis de la Banda y Lope Ruiz de Belmonte; en Reillo contra Sancho Rodríguez de Alcocer; en Valera de Suso contra Pedro de Valera y Pedro Sánchez de Olmeda y en Zarzuela y Chillarón contra Diego González de Cuenca. Tenían que vérselas por tanto con la flor y nata de los linajes arrendaticios de la ciudad, lo que explicaría, en gran medida, su escaso éxito a la hora de obtener el remate de las mismas. Por el contrario hubo poblaciones que no despertaron la ambición de estos personajes. Tondos y Arcos de la Cantera, sitas en el sexmo de Chillarón, nunca fueron objeto del deseo de nadie, salvo de sus respectivos concejos ${ }^{57}$. Semejante desproporción entre unas poblaciones y otras no sería tanto una cuestión monetaria, como de coincidencia de intereses en un sexmo concreto, dado estas familias no tenían ningún reparo en pujar rentas de escasa cuantía ${ }^{58}$.

Respecto a la ubicación por sexmos, el mayor número de aldeas pujadas correspondían a las demarcaciones de la Sierra con La Puerta, Cereceda y Mantiel y a Chillarón con Arcos de la Cantera, Chillarón y Tondos. Le seguían con dos el sexmo de Altarejos con Campillo de Altobuey y Valera de Suso, el de Arcas con La Parra y Reillo, mientras que el del Campo y Torralba sólo contaban con una aldea cada uno: Zarzuela y Albalate. Por otro lado, había varias poblaciones de señorío como eran Huélamo y los lugares de Córcoles y Valdeloso. Las alcabalas más valiosas eran las del sexmo de Altarejos, mientras que las más baratas eran las de Chillarón, el sexmo de la Sierra y Arcas.

Los concejos no solicitaban el arrendamiento ellos mismos, sino que diputaban procuradores, que podían actuar de manera individual, caso de los sexmos de la Sierra, el Campo, Torralba y Chillarón ${ }^{59}$ o en conjunto, siendo esto último más común en los sexmos restantes y en los lugares del monasterio de Monsalud $^{60}$. Todos los representantes eran vecinos del lugar, lo cual era lógico,

${ }^{57}$ A.M.C.U.-Legajo 140-Expediente 4 (Alcabalas de 1467), fols. 21r-22r.

${ }^{58}$ Es el caso de Diego González de Cuenca que en 1468 pujó las alcabalas de Embid y Verdelpino, las cuales sumadas, tan sólo valían 130 maravedís. A.M.C.U.-Legajo 140-Expediente 5 (Alcabalas de 1468), fol. 22 r.

59 Juan Bernal representó a La Puerta, Juan Fernández Serrano a Cereceda y Diego Martínez a Mantiel. En el caso de Zarzuela el elegido fue Juan Racionero. En las aldeas de Chillarón los elegidos fueron Juan González para Arcos de la Cantera, Miguel Martínez de Peñalver para Tondos y Gil Martínez de Chinchilla para Chillarón. Ver: A.M.C.U.-Legajo 140-Expediente 4 (Alcabalas de 1467), fols. 18v-22r. Para Albalate, sita en el sexmo de Torralba, se escogió a Alonso Fernández de Illana. Ver: A.M.C.U.-Legajo 140-Expediente 5 (Alcabalas de 1468), fols. 24v-25r.

60 En Arcas hallamos las dos modalidades. Enrique Escudero representó al concejo de La Parra en 1467 y Juan de Arnedillo a Reillo ese mismo año. Idem, fols. 29v-30v. Sin embargo, en 1469 la primera localidad hizo uso de una procuración formada por tres hombres: Gil Martínez de la Parra, Pedro Martínez, que era escudero y Juan García Grande. A.M.C.U.-Legajo 140-Expediente 6 (Alcabalas de 1469), fol. 16v. En Altarejos las procuraciones siempre fueron colectivas: las dos de Campillo en 1467 y la de Valera de Suso en 1469. Idem, fols. 25r y 28v-29r. AMCU-Legajo 140-Expediente 6 (Alcabalas de 1469), 
pero en ninguna de estas delegaciones se menciona la presencia de un regidor o alto cargo municipal que la encabezase. Sin embargo, es bastante probable que algunos de ellos contasen con experiencia en los asuntos municipales, siquiera en los cargos más ínfimos de la administración local ${ }^{61}$. Son muy raros, no obstante, los casos en los que se menciona algún dato más aparte de su vecindad. A excepción de Pedro Martínez, del cual se indica su ocupación, escudero, desconocemos prácticamente todo de estos hombres. A modo orientativo, se puede señalar que en el ámbito nobiliario los escuderos podían actuar como procuradores de sus señores, por lo que su presencia en estas legaciones concejiles no sería tampoco extraña, dado que se debería disponer de gente experimentada en este campo ${ }^{62}$. Para los concejos de señorío sí hallamos algún alto cargo municipal. Se trata del alcalde Juan Pérez que ocupaba dicho cargo en Córcoles.

Por norma general los arrendamientos se hacían por un año, salvo en casos concretos que se podían ampliar a dos. Sería el caso de Córcoles y Valdeloso, lugares del monasterio de Monsalud, que en 1467 se arrendaron por este tiempo, debiendo pagarse 4.000 maravedís anuales, por el arrendamiento de 1466, e idéntica cifra por el del año siguiente ${ }^{63}$. $O$ de Huélamo cuyo concejo debía pagar 18.000 maravedís por los años 1469 y 1470. Asimismo se aprecia como una novedad la aparición de los pagos en especie. En Huélamo, junto al dinero, se incluía la obligatoriedad de pagar cierta cantidad de lana y queso ${ }^{64}$, mientras que en Campillo de Altobuey el pago consistía en diez pares de gallinas ${ }^{65}$.

\section{b) Los vecinos de la tierra}

Los vecinos de las aldeas de Cuenca también probaron suerte con los arrendamientos, concentrándose en la puja de ciertas alcabalas aldeanas, muchas de las cuales habían sido ignoradas por las élites urbanas y por los representantes de los municipios.

fol. 15r. Para Córcoles y Valdeloso en 1468 se documenta una procuración formada por Juan Pérez, alcalde de Córcoles y Bartolomé Sánchez vecino de Valdeloso. Idem, fols. 9v-10v.

61 En la aldea de Fuentes se escogían dos regidores, puesto que a finales del siglo XV y comienzos del XVI ocuparon 20 hombres conocidos y cuatro juramentados. Las personas que los ocupaban se ubicaban en un segmento socioeconómico medio-alto, siendo los más ricos los que más frecuentemente aparecían y los que copaban el puesto de regidor. SÁNCHEZ BENITO, J. M., «Estructura social» en EEM, 31 (2008), pp. 115-117.

62 Para los escuderos de la nobleza conquense ver: ORTEGA CERVIGÓN, J. I., «Por seruiçios muchos e buenos que me ha fecho. Los criados de las casas nobiliarias conquenses en la Baja Edad Media» en AEM, 39/2 (2009), pp. 7302-721, sobre todo pp. 707-708.

${ }^{63}$ Según parece dicha renta quedó sin arrendar en 1466, restando 1.800 maravedís por pagar. De 1468 debían abonar 2.200 maravedís y se les debían tener en cuenta otros 2.200 maravedís tomados por el obispo de Cuenca de las rentas de 1466. A.M.C.U.-Legajo 140-Expediente 4 (Alcabalas de 1467), fols. $9 \mathrm{v}-10 \mathrm{v}$.

${ }^{64}$ Cuatro arrobas de cada una. A.M.C.U.-Legajo 140-Expediente 6 (Alcabalas de 1469), fols. 12r-12v.

65 Idem, fol. 15r. 
Tabla 4: Rentas pujadas por los vecinos de la tierra de Cuenca (1464-1470)

\begin{tabular}{|c|c|c|c|c|}
\hline Año & Renta & Sexmo & Arrendadores & Cantidad \\
\hline 1467 & Zahorejas & Arcas & $\begin{array}{c}\text { Juan Fernández } \\
\text { Blanco/ Francisco } \\
\text { Fernández (V) }\end{array}$ & 10.200 \\
\hline 1467 & Peralveche & Sierra & Alonso Sánchez (V) & $1.326(\mathrm{TR})$ \\
\hline 1467 & Arbeteta & Sierra & $\begin{array}{c}\text { Alonso Sánchez } \\
\text { Blanco }(\mathrm{V})\end{array}$ & $1.222(\mathrm{R})$ \\
\hline $1466-1467$ & $\begin{array}{l}\text { Todo el sexmo } \\
\text { de la Sierra }\end{array}$ & Sierra & $\begin{array}{c}\text { Martín Jiménez (ve- } \\
\text { cino del Recuenco)/ } \\
\text { Fernando Díaz (ve- } \\
\text { cino de Villanueva)/ } \\
\text { Juan Toral (vecino } \\
\text { de Peñalén)/ Miguel } \\
\text { de Vano (vecinos de } \\
\text { Armallones) }\end{array}$ & 204.000 (R ) \\
\hline 1467 & Palomera & Chillarón & $\begin{array}{l}\text { Francisco de Cabre- } \\
\text { ra/ Alonso de Mon- } \\
\text { teagudo (V) }\end{array}$ & $3.100(\mathrm{R})$ \\
\hline 1467 & $\begin{array}{c}\text { Villar del Saz de } \\
\text { Arcas }\end{array}$ & Arcas & Gil Rubio (V) & $\begin{array}{c}\text { Mayor precio en } \\
\text { que se dio en } \\
1464 \text { y } 1465\end{array}$ \\
\hline 1467 & Chumillas & Altarejos & Martín Sánchez (V) & $2.142(\mathrm{TR})$ \\
\hline 1467 & $\begin{array}{c}\text { Villar del Saz de } \\
\text { Navalón }\end{array}$ & Chillarón & $\begin{array}{l}\text { Pedro Martínez de } \\
\text { Paracuellos/ Juan } \\
\text { Fernández }(\mathrm{V}) \\
\end{array}$ & $\begin{array}{c}\text { Mayor precio que } \\
\text { valieron en } 1464 \\
\text { y } 1465 \\
\end{array}$ \\
\hline 1467 & Colliga & Chillarón & $\begin{array}{c}\text { Juan Sánchez Ca- } \\
\text { vanda/ Miguel Sán- } \\
\text { chez (V) }\end{array}$ & $1.714(\mathrm{R})$ \\
\hline 1468 & $\begin{array}{c}\text { Arbeteta y Peral- } \\
\text { veche }\end{array}$ & Sierra & $\begin{array}{c}\text { Alonso Sánchez } \\
\text { Blanco }(\mathrm{V})\end{array}$ & $2.700(\mathrm{R})$ \\
\hline 1468 & Armallones & Sierra & $\begin{array}{c}\text { Pedro Adán/ Pedro } \\
\text { García (V) }\end{array}$ & $8.500(\mathrm{R})$ \\
\hline 1468 & $\begin{array}{l}\text { La Puerta, Man- } \\
\text { tiel y Cereceda }\end{array}$ & Sierra & $\begin{array}{c}\text { Alonso Sánchez } \\
\text { Blanco }(\mathrm{V})\end{array}$ & 7.300 \\
\hline 1468 & El Recuenco & Sierra & $\begin{array}{c}\text { Antón Sánchez/ } \\
\text { Juan de Mingo (V) }\end{array}$ & $17.500(R)$ \\
\hline 1468 & Portilla & & $\begin{array}{l}\text { Miguel Fernández } \\
\text { de Portilla }(\mathrm{V})\end{array}$ & 2.320 (TR) \\
\hline
\end{tabular}

(R) Rematadas (TR) Traspasos (V) Vecinos del lugar al que pujan 
Lo primero que llama la atención es la presencia de determinados lugares como Zahorejas, El Recuenco, o Armallones, sitios que no tenían un bajo valor arrendaticio. El Recuenco, por ejemplo, se remató en 17.500 maravedís, Armallones en 8.500 y Zahorejas por $10.200^{66}$. Otro aspecto a tener en cuenta es la predominancia absoluta del sexmo de la Sierra, con pocas localidades ajenas a él: tres de Chillarón y una tan sólo de Arcas. El resto de los sexmos ni aparecen, lo que podría explicarse por distintas razones. Desde luego estas poblaciones no fueron desdeñadas por su escasa valía, sino que tal vez influyeron otros factores: carencia de intereses de las élites urbanas en ese sexmo, lo que se vería subrayado por la ausencia de aldeas del Campo, Altarejos o Torralba o la fuerte inestabilidad en la zona debida a la difícil situación política, lo que retraía a los futuros inversores ${ }^{67}$. Tampoco cabe descartar la existencia de una clase alta rural, encabezada por personajes enriquecidos gracias a la ganadería y el trabajo en el campo, que habían amasado una pequeña fortuna y ahora se dedicaban a invertirla en estas rentas ${ }^{68}$.

Por tanto, el número de posibles candidatos debía ser, por fuerza bajo, y efectivamente así ocurre. Contamos apenas una veintena de nombres de los cuales tan sólo se repite el de Alonso Sánchez Blanco, que pujó a las alcabalas de Arbeteta, Peralveche, La Puerta, Mantiel y Cereceda ${ }^{69}$, aunque con cuantías bastante reducidas. De igual manera, cabe señalar que las asociaciones para realizar estas pujas fueron muy habituales y coinciden en general con las alcabalas de mayor precio, como podían ser las de El Recuenco, Zahorejas o la puja por entero efectuada al sexmo de la Sierra. Para realizar esta última se unieron nada menos que cuatro hombres, siendo lo habitual, en el resto de los casos, dos personas ${ }^{70}$.

Respecto al origen de los postores estos procedían, en su mayoría, del mismo pueblo a cuyas alcabalas optaban o cuando menos del mismo sexmo. Si se miran uno por uno los lugares, se puede observar que casi todos los interesados eran oriundos de dicha población. Es el caso de Pedro Martínez de Pa-

\footnotetext{
${ }^{66}$ A.M.C.U.-Legajo 140-Expediente 4 (Alcabalas de 1467), fols. 18r-18v. A.M.C.U.-Legajo 140-Expediente 5 (Alcabalas de 1468), fols. 14r-14v, 22r.

${ }^{67}$ El sexmo de la sierra fue uno de los más castigados por las acciones hostiles de los señoríos circundantes. A este respecto merece la pena consultar el artículo de Ortega Cervigón: ORTEGA CERVIGÓN, J. I, «Porque la lauor de la syerra es provechosa para los pastos». Conflictos económicos, territoriales y jurisdiccionales entre el Concejo de Cuenca y los vasallos de señorío (ca. 1400-1520)" en EEM, 31 (2008), pp. 37-96, en el cual se analiza el impacto y los pleitos sostenidos por la ciudad contra los vasallos señoriales, precisamente en el sexmo de la Sierra.

${ }^{68}$ En Fuentes, que de nuevo nos sirve como lugar de muestra, el número de arrendatarios de sisas y alcabalas era muy corto, pudiendo repetir en el cargo. SÁNCHEZ BENITO, J. M., "Estructura social..." en EEM, 31 (2008), p. 119. Además el único oficio que conocemos de los personajes implicados es precisamente el de boyerizo, ostentado por Miguel Sánchez, vecino de Colliga y que compaginaría con la actividad agrícola. A.M.C.U.-Legajo 140-Expediente 4 (Alcabalas de 1467), fols. 17r-17v.

${ }_{69}$ Acerca de las alcabalas de Arbeteta parece que las arrendó ejerciendo como procurador para el concejo, pero este extremo no queda muy claro. Idem, fol. 24r. A.M.C.U.-Legajo 140-Expediente 5 (Alcabalas de 1468), fols. 13v-14r, 20 r.

${ }^{70}$ Idem, fol. 42r.
} 
racuellos y Juan Fernández, vecinos de Villar del Saz de Navalón, que pujaron a las rentas de esa aldea, el de Juan Sánchez Cavanda y Miguel Sánchez, que aspiraban a las de Colliga o el de Pedro Adán y Pedro García con las de ArmaIlones ${ }^{71}$. Menos habitual era que en estos casos concurriesen vecinos de otros sitios o incluso de zonas de señoríos. En la puja por entero al sexmo de la Sierra hallamos un buen ejemplo de esto. En ella se incluían Martín Jiménez, vecino de El Recuenco, Fernando Díaz que lo era de Villanueva, Juan Toral, de Peñalén, lugar de señorío y Miguel de Vano que residía en Armallones ${ }^{72}$. El nivel de atracción no solía superar, sin embargo, los límites de los sexmos correspondientes. Así, Alonso Sánchez Blanco era vecino de Arbeteta y pujó a poblaciones cercanas como La Puerta, Mantiel o Cereceda, pero nunca a las de un sexmo distinto. Todo ello contrasta con el alto nivel de movilidad territorial del que hacían gala las élites urbanas, cuyos intereses se hallaban diseminados por toda la tierra.

Como punto final respecto a estos individuos haremos una mención breve a las cantidades manejadas en sus arrendamientos. En general, estas son bajas, lo que unido a las asociaciones existentes entre ellos nos indica que, a pesar de su riqueza, tampoco debían ser unos potentados, ya que necesitaban compartir los gastos de rentas situadas en un marco de unos 1.000-3.000 maravedís. Además, que tan sólo se repita el nombre de Alonso Sánchez Blanco, señala que estos personajes se lo jugaban todo a una carta, posiblemente porque tampoco podían repetir la experiencia y sus medios serían limitados, aunque cabe decir que de manera frecuente se vieron coronados con el éxito. De las trece pujas documentadas siete les fueron rematadas y además recibieron el traspaso de otras tres, con lo que muy pocas alcabalas escaparon de sus manos ${ }^{73}$.

\subsection{Otros personajes}

Finalmente en la nómina de arrendadores y postores para este período figuran una serie de individuos de difícil adscripción, por lo que los hemos incluido en un epígrafe aparte. Su posición social no está demasiado clara y en algunos casos, toda la información que tenemos de ellos se limita simplemente a señalar su vecindad en Cuenca sin dar más explicaciones ${ }^{74}$.

71 Idem, fols. $16 \mathrm{r}, 17 \mathrm{r}-18 \mathrm{r}$. Ibidem, fols. $14 \mathrm{r}-14 \mathrm{v}$.

72 Idem, fol. 42r.

73 Se trata de Peralveche traspasada por Sancho García de Alcocer y de Chumillas traspasada por Nicolás García de Garanatea. A.M.C.U.-Legajo 140-Expediente 4 (Alcabalas de 1467), fols. 14v y 23r. En el caso de Portilla, el anterior propietario era Martín de Requena. A.M.C.U.-Legajo 140-Expediente 5 (Alcabalas de 1468), fol. 25v.

74 Serían los casos de Álvaro de Arzales, Juan de Andújar, Gil Ibáñez y Francisco Sánchez el Mozo. Para los casos de 1467 ver: Idem, fol. 22v. Para 1468, ver: Idem, fol. 25v. 
Tabla 5: Arrendadores y postores de alcabalas de procedencia social desconocida (1464-1470)

\begin{tabular}{|c|c|c|c|c|}
\hline Año & Renta & Sexmo & Arrendador & Cantidad \\
\hline 1467 & La Puerta & Sierra & $\begin{array}{l}\text { Alvaro de Arzales } \\
\text { (C) }\end{array}$ & $\begin{array}{l}\text { Mayor precio que se } \\
\text { dio en } 1464 \text { y } 1465\end{array}$ \\
\hline 1467 & $\begin{array}{l}\text { Fresneda [de } \\
\text { la Sierra] }\end{array}$ & Campo & $\begin{array}{l}\text { Juan de Andújar } \\
\text { (C) }\end{array}$ & 550 \\
\hline $1466-1467$ & $\begin{array}{l}\text { Sexmos del } \\
\text { Campo, Chilla- } \\
\text { rón y Torralba }\end{array}$ & $\begin{array}{l}\text { Campo, } \\
\text { Chillarón, } \\
\text { Torralba }\end{array}$ & Martín Martínez & $\begin{array}{l}66.000 \text { por los tres } \\
\text { sexmos }\end{array}$ \\
\hline 1467 & $\begin{array}{l}\text { Ribatajadilla, } \\
\text { Ribagorda y } \\
\text { Villaseca }\end{array}$ & Campo & Juan de Andújar & 1.800 \\
\hline 1467 & $\begin{array}{l}\text { Sexmo de la } \\
\text { Sierra }\end{array}$ & Sierra & Martín Toledano & 4.000 \\
\hline 1467 & Castillejos & Torralba & Antón de Pareja & 1.500 \\
\hline 1467 & Albalate & Torralba & Antón de Pareja & 1.350 \\
\hline 1467 & $\begin{array}{l}\text { La Parra, } \\
\text { Tórtola y Chu- } \\
\text { millas }\end{array}$ & $\begin{array}{l}\text { Altarejos, } \\
\text { Arcas }\end{array}$ & $\begin{array}{c}\text { Nicolás García de } \\
\text { Garavatea }\end{array}$ & $\begin{array}{c}\text { Mayor precio en que } \\
\text { se dio en } 1464 \text { y } \\
1465 \text { (Rematadas) }\end{array}$ \\
\hline 1467 & Reillo & Arcas & $\begin{array}{c}\text { Nicolás García de } \\
\text { Garavatea }\end{array}$ & $\begin{array}{c}50 \text { maravedís más } \\
\text { de lo que valieron } \\
\text { en } 1464 \text { y } 1465\end{array}$ \\
\hline 1467 & Tórtola & Arcas & $\begin{array}{c}\text { Nicolás García de } \\
\text { Garavatea }\end{array}$ & 1.020 \\
\hline 1467 & $\begin{array}{l}\text { Sexmos de } \\
\text { Altarejos y } \\
\text { Arcas }\end{array}$ & $\begin{array}{l}\text { Altarejos, } \\
\text { Arcas }\end{array}$ & $\begin{array}{c}\text { Nicolás García de } \\
\text { Garavatea }\end{array}$ & $\begin{array}{l}1.500 \text { maravedís } \\
\text { más de lo que valie- } \\
\text { ron en } 1464 \text { y } 1465\end{array}$ \\
\hline 1467 & $\begin{array}{l}\text { Córcoles y } \\
\text { Valdeloso }\end{array}$ & & $\begin{array}{l}\text { Martín de Santa- } \\
\text { nilla }\end{array}$ & 3.170 \\
\hline 1467 & Valdeganga & Arcas & Juan de Burgos & 1.510 \\
\hline 1467 & Tórtola & Arcas & Juan de Burgos & 500 \\
\hline 1467 & La Parra & Arcas & Juan de Burgos & 1.860 \\
\hline
\end{tabular}




\begin{tabular}{|c|c|c|c|c|}
\hline Año & Renta & Sexmo & Arrendador & Cantidad \\
\hline 1467 & Chumillas & Altarejos & $\begin{array}{c}\text { Nicolás García de } \\
\text { Garavatea }\end{array}$ & $\begin{array}{c}\text { Mayor precio en } \\
\text { que se dio en } 1464 \\
\text { y } 1465\end{array}$ \\
\hline 1467 & Requena & & Fernán Picazo & 50.000 \\
\hline 1467 & $\begin{array}{l}\text { Campillo de } \\
\text { Altobuey }\end{array}$ & Altarejos & $\begin{array}{c}\text { Nicolás García de } \\
\text { Garavatea }\end{array}$ & $\begin{array}{c}100 \text { maravedís más } \\
\text { de lo que valieron } \\
\text { en } 1464 \text { y } 1465\end{array}$ \\
\hline 1467 & Colliga & Chillarón & Gómez Suárez & $\begin{array}{c}\text { Mayor precio que } \\
\text { valieron en } 1464 \mathrm{y} \\
1465\end{array}$ \\
\hline 1467 & $\begin{array}{l}\text { Córcoles y } \\
\text { Valdeloso }\end{array}$ & & $\begin{array}{c}\text { Ruy González } \\
\text { Zaragozano }\end{array}$ & 2.000 \\
\hline 1467 & $\begin{array}{l}\text { Córcoles y } \\
\text { Valdeloso }\end{array}$ & & $\begin{array}{c}\text { Rodrigo Zarago- } \\
\text { zano }\end{array}$ & 3.000 \\
\hline 1468 & $\begin{array}{l}\text { Ribatajadilla, } \\
\text { Ribagorda, } \\
\text { Fresneda de } \\
\text { la Sierra y Vi- } \\
\text { Ilaseca }\end{array}$ & Campo & Juan de Andújar & $\begin{array}{c}\text { Mayores precios en } \\
\text { que se pusieron en } \\
1464 \text { y } 1465\end{array}$ \\
\hline 1468 & Palomares & Sierra & $\begin{array}{l}\text { Gil Ibáñez / Fran- } \\
\text { cisco Sánchez el } \\
\text { Mozo (C) }\end{array}$ & 3.100 \\
\hline $\begin{array}{c}1466 \text { (arren- } \\
\text { dadas en } \\
1468)\end{array}$ & Sotos & Campo & $\begin{array}{c}\text { Martín González } \\
\text { de Toledo }\end{array}$ & 3.000 \\
\hline 1468 & $\begin{array}{l}\text { Villar de Do- } \\
\text { mingo García }\end{array}$ & Torralba & Juan Redondo & 2.460 \\
\hline 1468 & $\begin{array}{c}\text { La Parra, } \\
\text { Valdeganga, } \\
\text { Tórtola, Reyllo, } \\
\text { Chumillas }\end{array}$ & $\begin{array}{l}\text { Altarejos, } \\
\text { Arcas }\end{array}$ & $\begin{array}{c}\text { Nicolás García de } \\
\text { Garavatea }\end{array}$ & $\begin{array}{c}\text { Precios que más } \\
\text { valieron en } 1464 \text { y } \\
1465\end{array}$ \\
\hline 1469 & $\begin{array}{l}\text { Todos los sex- } \\
\text { mos }\end{array}$ & & Mosé Abenxuxé & 91.000 \\
\hline
\end{tabular}

(C) Vecino de Cuenca

Casi ninguno de los individuos aquí citados, tienen más referencias que su profesión o su procedencia y en raras ocasiones tenemos la fortuna de contar con ambas. 
Una de las excepciones sería Juan de Andújar, del que además de vecino de Cuenca, se refiere su profesión, jubonero y repite pujas hasta en tres ocasiones ${ }^{75}$. De otros conocemos su profesión como en los casos de Nicolás García de Garavatea ${ }^{76}$, Juan Redondo, cardador ${ }^{77}$; Martín González de Toledo, que era joyero ${ }^{78}$; Martín Martínez, que era criado ${ }^{79}$; o Antón de Pareja, que oficiaba como barbero ${ }^{80}$.

Algunos podrían hallarse ligados a la élite urbana posiblemente por lazos de tipo económico o clientelar. Es muy interesante comprobar quienes son los fiadores de estos personajes, dado que podían ser avalados por individuos con gran experiencia en el arrendamiento de las rentas o con una elevada posición social. Un buen ejemplo de ello lo tenemos con Juan de Andújar, cuyo avalista era Diego González de Cuenca, uno de los grandes arrendadores de los sexmos conquenses y más concretamente en el del Campo, donde hizo ofertas con gran asiduidad $^{81}$. La coincidencia de ambos en el mismo sexmo, podría incluso llevarnos a pensar que dichos grandes arrendadores procuraban controlar, al menos en parte, la citada circunscripción por medio de terceros que arrendaban las rentas a las que ellos no podían llegar. Un caso similar sería el de Juan Redondo, cuyos fiadores eran dos miembros de la élite de participación, Juan de la Bachillera y Alonso de Ocales ${ }^{82}$. Incluso los señores territoriales podían aparecer como fiadores de criados suyos, posiblemente para garantizarse el control de ciertas alcabalas, como ocurrió con las de Córcoles y Valdeloso, a las que presentó postura un criado de Alvaro de Luna, señor de San Millán ${ }^{83}$. También podía darse el caso de que detrás de un grupo de arrendadores se hallasen los hacedores de las rentas. Estos personajes eran los encargados de controlar todo el proceso de arrendamiento de las rentas menores, marcando las pautas a seguir por los futuros arrendadores en todo lo concerniente a plazos, precios, condiciones y formas del remate. De ahí este nombre con el que aparecen identificados en la documentación conquense ${ }^{84}$.

75 A.M.C.U.-Legajo 140-Expediente 4 (Alcabalas de 1467), fols. 17r, 61v-62r y 63v. A.M.C.U.-Legajo 140-Expediente 5 (Alcabalas de 1468), fol. 8r.

76 Así consta en 1467 como escribano. Idem, fols. 5v y $12 \mathrm{v}$.

77 Ibidem, fol. 24r.

78 Es posible que él y Martín Toledano, que también era joyero, sean la misma persona. Para las referencias de 1467 ver: Ibidem, fol. 4v. Para las de 1468: Idem, fol. 27r. Sin embargo, este personaje también consta como tendero en las condiciones de las alcabalas de 1469 y 1470. A.M.C.U.-Legajo 140-Expediente 6 (Alcabalas de 1469), fols. 13v-14r. A.M.C.U.-Legajo 140-Expediente 7 (Alcabalas de 1470), fol. 8 r.

79 Lo documentamos en 1468. Idem, fol. 42r.

80 Aparece en 1467. Idem, fol. 63v.

81 A.M.C.U.-Legajo 140-Expediente 4 (Alcabalas de 1467), fols. 17r, 61v-62r y 63v. A.M.C.U.-Legajo 140-Expediente 5 (Alcabalas de 1468), fol. 8r.

82 Idem, fol. 60v. Alonso de Ocales fue fiel de la caballería de la sierra en 1463 y 1464, período en el cual pudo tejer una red de intereses en la tierra de Cuenca. Su familia estaba muy ligada a los Acuña. Por su parte, los Bachillera eran expertos en las cuestiones arrendaticias y de aprovisionamiento de la ciudad, siendo uno de sus socios más habituales, como fiadores, los Ocales. JARA FUENTE, J. A., Concejo..., pp. 213 y 215.

83 Idem, fol. 49r.

${ }^{84}$ Así consta en los cuadernos de arrendamiento de Cuenca. Sería el caso de Alonso Bordallo y Juan de San Pedro, en 1467, Idem, fols. 4v, 41r y 69v; Juan de Valladolid y Alonso de Bozmediano en 
Para este supuesto hallamos indicios de que uno de los hacedores, concretamente Juan de San Pedro, que ejerció el cargo en 1467 y $1468^{85}$, avaló en esos años a Martín Martínez, que era criado suyo. En otras ocasiones eran los miembros de la élite de participación los que avalaban a sus sirvientes, como hizo Martín González de Toledo, el cual fió a un criado suyo llamado Pedro de Xaona ${ }^{86}$.

Por tanto, dentro de este grupo se puede apreciar que no eran extraños los lazos con el ámbito urbano y sus élites, e incluso con la nobleza territorial. Esto contrasta con la escasa información que tenemos para algunos de los nombres que aparecen: Gómez Suárez, Antón de Pareja o Ruy González Zaragozano, nos son casi desconocidos, e incluso Nicolás García de Garavatea, que era el arrendador más importante de estos personajes, queda un tanto difuso. Sabemos que formó parte de diversas comisiones urbanas, pero en sus negocios en la tierra no consta fiador alguno. A pesar de ello debía estar bien relacionado con las élites urbanas lo que explicaría su fuerte posición en los sexmos de Arcas y Altarejos. Mayor claridad existe en torno a Mosé Abenxuxé. Este era de origen judío y familiar cercano de Yucaf Abolafia, que fue hacedor en 1469. Con ello queda claro que podía pujar por todos los sexmos de Cuenca a la vez, tal y como hizo en 1469 y que además podía ofrecer generosas posturas por la alcabala de la carne tal y como hizo en 1467,1468 y $1469^{87}$.

\section{CONCLUSIONES}

Con el presente artículo hemos intentado establecer quienes ejercieron el cargo de arrendadores de las alcabalas en la tierra de Cuenca. Como se ha podido ver, el papel principal lo ostentaban los linajes de participación municipales, los cuales por su propia idiosincrasia eran los más interesados en el arrendamiento de las rentas, que les servían como medio de vida y además como vía de ascenso social. Sus intereses se centraban en zonas muy concretas de la tierra, coincidiendo así con sus intereses ganaderos, patrimoniales o textiles. En una menor medida aparecen los linajes regimentales, pero como su supervivencia dependía más de sus propiedades ganaderas o inmobiliarias no se inmiscuyeron mucho en esta cuestión.

1468, Ibidem, , fol. 1r; Pedro Fernández de Toledo, Jerónimo de Toro y Daví Cohen en 1469, A.M.C.U.Legajo 140-Expediente 6 (Alcabalas de 1469), fols. 6r-6v y 10r; Daví Cohen en 1470, A.M.C.U.-Legajo 140-Expediente 7 (Alcabalas de 1470), fol. 5r.

85 Juan de San Pedro era escribano de cámara del rey y vecino de Madrid. Idem, fol. 56r.

86 Idem, fol. 42r. Ibidem, fol. 27r.

87 Era hijo de David Abenxuxé y pertenecía a la aljama de Huete. Además era carnicero y pujó a este producto en 1467, 1468 y 1469. A.M.C.U.-Legajo 140-Expediente 4 (Alcabalas de 1467), fol. 7v. A.M.C.U.-Legajo 140-Expediente 5 (Alcabalas de 1468), fols. 16r y 30v. A.M.C.U.-Legajo 140-Expediente 6 (Alcabalas de 1469), fol. 17r. 
A pesar de su preponderancia los linajes urbanos tuvieron que afrontar la competencia de otros actores, menores, pero que podían ser importantes según el lugar o el tipo de renta. Los concejos de la tierra y los vecinos de la misma se concentraban en las alcabalas de sus localidades o, como mucho, los segundos podían optar a las de algunas poblaciones cercanas. En general, se trataba de rentas de escaso valor, lo que no quitaba para que en ocasiones, estas instituciones y estas personas pudiesen pujar a rentas de mayor cuantía e interés.

Junto a todos ellos aparece un último grupo de personas, algunas de ellas poco conocidas, pero muy interesantes, dado el papel activo que algunos desempeñaron. Aún así, salvo casos concretos como Nicolás García de Garavatea, pocos destacaron. 
